\title{
Plasma-Radiofrequency Interactions Around Atmospheric Re-Entry Vehicles: Modelling and Arc-Jet Simulation
}

\author{
R. Savino*, D. Paterna, M. De Stefano Fumo and M. D’Elia \\ Department of Aerospace Engineering, University of Naples “Federico II” (DIAS), Italy
}

\begin{abstract}
An aero-thermo-chemical model is developed to simulate the flowfield, including ionization, around atmospheric re-entry configurations, and its interactions with radio-frequency communication signals (e.g. GPS). The model is successfully validated against literature in-flight measurements of the electron number density, and then applied to the re-entry of recently proposed concepts of slender configurations. The advantages of using sharp and slender geometries for re-entry applications, with respect to radio communication problems, are analyzed and discussed.

In addition, an experimental test-bed in an arc-jet plasma wind-tunnel has been setup to reproduce on ground the plasmaradiofrequency interaction. The capability to duplicate on-ground the ionization levels encountered during re-entry has been successfully demonstrated. A numerical model of an Argon plasma jet in chemical and thermal non-equilibrium has also been developed, for numerical rebuilding of the experiments. Both electron number densities and electron temperatures have been successfully correlated, demonstrating the ability of arc-jet facilities, integrated with proper numerical tools, to correctly deal with problems of communication attenuation/black-out.
\end{abstract}

Keywords: Hypersonic flow, atmospheric re-entry, communication black-out.

\section{INTRODUCTION}

The Aerothermodynamic research group of the Department of Aerospace Engineering (DIAS) of the University of Naples "Federico II" has been involved for over 20 years in research studies in the field of hypersonic aerodynamics and aerothermochemistry. Recently, the research activities have been focused on the study of advanced aerodynamic configurations for re-entry vehicles and on new composite ceramic materials able to withstand ultra high temperatures (above $2000^{\circ} \mathrm{C}$ ) in oxidizing environments.

A large effort has been dedicated to investigate new strategies for atmospheric re-entry of spaceplane vehicles that, in contrast to conventional blunt configurations, are characterised by sharp leading edges of wings and fins, made of Ultra High Temperature Ceramic (UHTC) materials, high lift-over drag, low wing loading, which allows the vehicle to fly at comparatively small angle of attack during re-entry, in comparison to conventional re-entry vehicles.

The activities include computation of re-entry trajectories, evaluation of aerodynamic databases and aeroheating computations at the most severe re-entry conditions.

In this framework, recent attention has been dedicated to the study of the problem of the telecommunications blackout along the re-entry trajectory of low-wing-loading winged spaceplanes, for its importance related to guidance, navigation and control issues for this type of vehicles. In

*Address correspondence to this author at the Department of Aerospace Engineering, University of Naples "Federico II" (DIAS), Italy; Tel: +390817682357; Fax: +39-0817682351; E-mail: rasavino@unina.it principle, we expect signal attenuation due to the plasma sheath around this kind of vehicles to be lower, in comparison to capsules or vehicles with high wing loading. Indeed, low wing loading allows flight at low angles of attack, or reduced relative bluntness of the vehicle, compared to conventional re-entry systems. Small bluntness is a dominating effect in the reduction of the shock wave strenght, and, as a consequence, of the level of gas ionisation, which, in turn, influences the radio communication black-out.

The interaction between radiowaves and plasma environments is in fact an area of continuing interest in Aerospace research. Vehicles travelling at hypersonic speeds can experience degradation of radio communications, including GPS navigation links, because of effects arising from intense ionization of the surrounding air. In fact, during hypersonic re-entry flight, the shock wave detached from the vehicle leading edges and the shear layer neighbouring the body heat the air and generate a ionized plasma layer that is known to degrade the quality of radiowave signal propagation. Three are the main influencing parameters for this phenomenon, geometry, Mach number (i.e. the shockstrength), and altitude, all of which determine the ionization level inside the shock layer. Fig. (1) shows the typical altitude-velocity conditions at which black-out phenomenon occurs for three different re-entry vehicles, characterized by different aerodynamic configurations. As can be inferred from figure, the onset of black-out occurs at about $80-85 \mathrm{~km}$, where the high temperatures behind the strong shock (Mach number $>20$ ) promote dissociation and ionization. Furthermore, the relatively low pressure conditions at high altitudes decrease the recombination rates and allow the flow of the free electrons from the stagnation area to the rear of 
the vehicle, where transmitting/receiving antennas are usually located. The aerothermodynamic conditions for the recovery of telecommunications depend on the vehicle trajectory and geometric configuration. For instance, for Space Shuttle and capsules, like the ARD, the recovery altitude has been shown to be around 40-50 km [1], while around $25 \mathrm{~km}$ for the RAM-C experimental vehicle [2]. As a general rule, the steeper the trajectory (and therefore the higher the Mach number for a given altitude), the lower is the altitude at which recovery occurs.

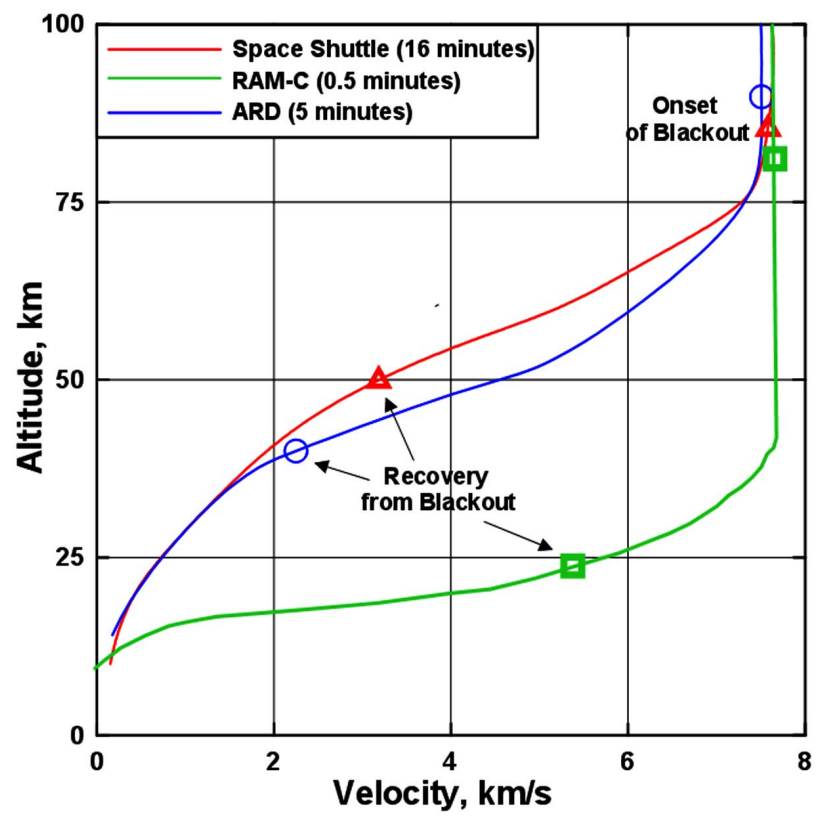

Fig. (1). Re-entry trajectories and blackout range for Space Shuttle, RAM-C and ARD.

The blackout phenomenon first came to the public's attention during the 1960's [3], when humans began traveling in space, and jumped to the forefront of the public eye during Apollo 13's failed attempt at a moon landing. During the return, NASA engineers were not sure whether the capsule was re-entering the atmosphere at the correct angle. The blackout lasted longer than was expected, about six-minute, in which there was no way for mission control to know what was happening onboard the capsule or the status of the crew.

When the US began using the space shuttle to ferry humans to and from space, and with the launch of the Tracking and Data Relay Satellite (TDRS) system, the blackout phenomenon was no longer an issue because the orbiter is not fully encapsulated in plasma during atmospheric re-entry. Due to the shape of the orbiter, areas on the top of the vehicle are not engulfed in the plasma sheath, allowing radio signals to be sent from the orbiter to TDRS in orbit, and then be relayed back down to earth. However, re-entry blackout is still a problem for the human space flight programs. One example of a sample return mission that crashed due to an error during the re-entry phase is the Genesis mission. Upon re-entry, a sensor failure prevented the drogue parachute from opening and decelerating the capsule, letting it crash into the Utah desert.
This failure could have been prevented by mission control in constant contact with the re-entry vehicle.

After the tragic accident in 2003 of Columbia, NASA decided to retire the Space Shuttle early and desire to return to the moon, developing the crew exploration vehicle (CEV) with the Orion capsule-type re-entry vehicle, so that communications blackout will again be an issue for future human spaceflight.

Furthermore, future hypersonic high lift spaceplanes for human spaceflight, space tourism or military applications will require telecommunications improvement during flight at hypersonic speeds. Main replacement is to have constant sensor and telemetry communication with the vehicle and partially Global Positioning Satellite (GPS) for greater accuracy in achieving the destination target.

Signal attenuation in plasma is caused by the free electrons in the gas and also include, in addition to magnitude attenuation, phase shift, noise, etc, whose entities are directly related to the electron number density, or, the plasma frequency. The radio blackout occurs when the plasma frequency is higher than the radiowave frequency. In this case, the radio wave signals to and from the vehicle are reflected or attenuated so that the vehicle loses voice communication, data telemetry, and Global Positioning System navigation.

Fundamental theoretical background for radio-frequency (RF) black-out during re-entry was provided by the works of Dunn and Kang [4] and Evans et al. [5]. They obtained good agreement with data from the Radio Attenuation Measurements (RAM) experiments.

The former studied a chemical model initially made by 12 species and 64 reactions, but subsequently, they reduced the calculations to 11 fundamental species $\left(\mathrm{O}_{2}, \mathrm{~N}_{2}, \mathrm{~N}, \mathrm{O}\right.$, $\left.\mathrm{NO}, \mathrm{NO}^{+}, \mathrm{O}^{+}, \mathrm{N}^{+}, \mathrm{O}_{2}{ }^{+}, \mathrm{N}_{2}{ }^{+}, \mathrm{e}-\right)$ and 26 reactions, showing the importance of including the $\mathrm{O}^{+}, \mathrm{N}^{+}, \mathrm{N}_{2}^{+}, \mathrm{O}_{2}^{+}, \mathrm{NO}^{+}$ionization reactions.

Evans et al. [5] focused on studying the effects of ambipolar diffusion applied to a boundary layer method for altitudes below $70 \mathrm{~km}$, comparing their results with the RAM C data. They obtained good agreement, especially at relatively small distances from the body wall, using a very 'slim' non-equilibrium chemical model of 7 species $\left(\mathrm{O}_{2}, \mathrm{~N}_{2}\right.$, $\left.\mathrm{N}, \mathrm{O}, \mathrm{NO}, \mathrm{NO}^{+}, \mathrm{e}^{-}\right)$and the only $\mathrm{NO}^{+}$ionization reaction.

Radio-Frequency black-out was experienced during the recent Mars Pathfinder missions, when for a 30 seconds period, the $\mathrm{X}$ band antenna communications link was lost. Morabito [6] simulated the martian re-entry mission with two numerical methods, Horton and LAURA, developed respectively by JPL and by the Langley research centre. The work particularly focused on studying the wake-region electronic density, where the $\mathrm{X}$ band antenna was located. It also simulated the Apollo mission re-entry phase to further validate the model by comparisons with other experimental data.

Hartunian et al. [2] focused on RF black-out causes and possible mitigation schemes (i.e. methods to solve or 
mitigate the black-out occurrence), studying the electron densities around possible Reusable Launch Vehicles (RLV) geometries, i.e. mainly sharp geometries, and evaluated the antennas performances as function of plasma parameters. At high altitudes, a result of zero attenuation was obtained. However their results didn't agree completely at lower altitudes with the available flight experimental results. A few mitigation schemes, both passive and active, were proposed like the injections of quenchants, e.g. water and electrophilics, the utilization of magnetic field windows and multiarray antennas for enhancing GPS reception. However, aerodynamic shaping was found to be the most promising way of solution of the RF black-out problems; this argument has been resumed in the present study and further developed.

A very comprehensive review on the state-of-art of communications blackout phenomena during atmospheric reentry can be found in [7-10].

The present article deals with a suitable plasma flow modelling, used to assess the typical plasma frequencies around space vehicles during atmospheric re-entry and with an experimental set-up, based on an arc-jet facility, to measure electron density and plasma frequencies related to radio-frequency signal loss or attenuation. These activities can be integrated to define a unique simulator environment to study the plasma/radio-frequency interactions on ground and to extrapolate the results to flight conditions.

\section{NUMERICAL MODEL}

\subsection{Fluid Dynamic Model}

The problem of radio wave attenuation or blackout through plasma can be briefly summarized following [11]. Let us consider a re-entry vehicle travelling in the atmosphere at hypersonic velocity. The flowfield around the vehicle forebody is characterized by a number of physical effects including: shock layer, entropy layer, boundary layer, chemical nonequilibrium in the stagnation region, flow expansion onto the forebody causing partial chemical freezing of ionization at a nonequilibrium state, surface enhancement of chemical reactions, etc. Consider now an antenna on the body surface. The antenna transmits electromagnetic radiation in the form of microwave signal for purposes of communication, sensing or telemetry through a layer of ionized gas of variable thickness along the antenna aperture. The interaction of the electromagnetic radiation with the ionized gas flowfield causes several effects: the signal propagation path is altered with a phase shift and a loss in signal strength due to attenuation (power or energy loss changes the intensity of the wave), the antenna free space radiation pattern and admittance properties are modified. All these effects depend on the properties of the ionized gas, that must be properly modelled.

In this paper, the plasma flow field around a typical reentry vehicle has been evaluated through Computational Fluid Dynamics.

A numerical model for plasma flow simulations has been developed, based on literature data concerning thermodynamic properties of gas species and kinetic rates of the related chemical reactions. Different models exist in literature $[4,5,12,13]$ for the study of air plasma ionization. In particular, the models by Dunn and Kang and Evans have been specifically developed for the study of plasmaradiofrequency interaction, and are taken as reference in the present paper. Two chemical models have been taken into account, both including 9 chemical species: $\left(\mathrm{O}_{2}, \mathrm{~N}_{2}, \mathrm{O}, \mathrm{N}\right.$, $\left.\mathrm{NO}, \mathrm{NO}^{+}, \mathrm{O}_{2}{ }^{+}, \mathrm{N}_{2}{ }^{+}, \mathrm{e}^{-}\right)$. It must be noted that electron is treated as an additional, independent, gas species. Thermodynamic properties of the species present in the mixture have been taken by $[14,15]$. The pressure of the mixture is expressed by the Dalton's law, and mixture rules are used to obtain the mixture transport properties (in particular, the Wilkey's rule). The difference between the two chemical models concerns the chemical reaction rates, which are taken from two different sources $[4,5]$ The list of the chemical reactions taken into account is shown in Table 1. It has been verified, by numerical experiments in the range of velocities between 6 and $10 \mathrm{~km} / \mathrm{s}$, that the inclusion of the associative ionization reactions, i.e. $\mathrm{N}+\mathrm{N} \Leftrightarrow \mathrm{N}_{2}{ }^{+}+\mathrm{e}^{-}$and $\mathrm{O}$ $+\mathrm{O} \Leftrightarrow \mathrm{O}_{2}{ }^{+}+\mathrm{e}^{-}$, is essential to obtain a good correlation with the in-flight measurements.

For the vehicle configurations and the flight conditions considered in the present work, the flow can be considered laminar, viscous, in chemical non-equilibrium and in thermal equilibrium, following [4].

The flow equations have been solved with the Fluent code [16], adopting in particular its AUSM+ scheme for convective numerical fluxes, and customized with appropriate functions to implement the described thermochemical model.

For each simulation, a grid convergence procedure has been implemented, to ensure grid independence of the solution.

Table 1. Chemical Reactions Considered in the Numerical Model

\begin{tabular}{|c|c|}
\hline Reaction & Third Body $\boldsymbol{M}$ \\
\hline \hline $\mathrm{O}_{2}+\mathrm{M} \Leftrightarrow \mathrm{O}+\mathrm{O}+\mathrm{M}$ & $\mathrm{N}_{2}, \mathrm{O}_{2}, \mathrm{NO}, \mathrm{N}, \mathrm{O}$ \\
\hline $\mathrm{N}_{2}+\mathrm{M} \Leftrightarrow \mathrm{N}+\mathrm{N}+\mathrm{M}$ & $\mathrm{N}_{2}, \mathrm{O}_{2}, \mathrm{NO}, \mathrm{O}$ \\
\hline $\mathrm{N}_{2}+\mathrm{N} \Leftrightarrow \mathrm{N}+\mathrm{N}+\mathrm{N}$ & $\mathrm{O}_{2}, \mathrm{NO}, \mathrm{N}, \mathrm{O}$ \\
\hline $\mathrm{NO}+\mathrm{M} \Leftrightarrow \mathrm{N}+\mathrm{O}+\mathrm{M}$ & $\mathrm{N}_{2}, \mathrm{O}_{2}, \mathrm{NO}, \mathrm{N}, \mathrm{O}$ \\
\hline $\mathrm{NO}+\mathrm{O} \Leftrightarrow \mathrm{O}_{2}+\mathrm{N}$ & \\
\hline $\mathrm{N}_{2}+\mathrm{O} \Leftrightarrow \mathrm{NO}+\mathrm{N}$ & \\
\hline $\mathrm{N}+\mathrm{O} \Leftrightarrow \mathrm{NO}^{+}+\mathrm{e}^{-}$ & \\
\hline $\mathrm{N}+\mathrm{N} \Leftrightarrow \mathrm{N}_{2}{ }^{+}+\mathrm{e}^{-}$ & \\
\hline $\mathrm{O}+\mathrm{O} \Leftrightarrow \mathrm{O}_{2}{ }^{+}+\mathrm{e}^{-}$ & \\
\hline & \\
\hline
\end{tabular}

The code has been validated by means of literature data regarding the Radio Attenuation Measurement (RAM) C flight experiment [17], as shown in the following. To correlate these data, a meshed geometry of the RAM C-II shape (Fig. 2), was generated and numerical simulations of 
the flow field were carried out with the developed thermochemical model. Fig. (3) shows the electron number density at two grid levels. The maximum electron density, computed on the finest grid, differs no more than 5\% from the coarsest grid results. Calculations on an intermediate grid level, $40 \times 100$, exhibit negligible differences with the finest grid level, and are not reported in the graph.

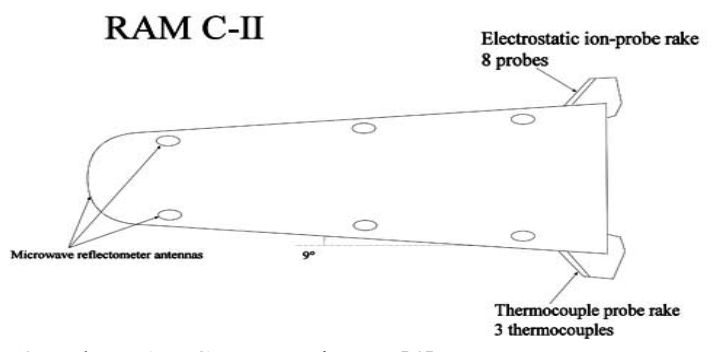

Fig. (2). The RAMC-II experiment [4].

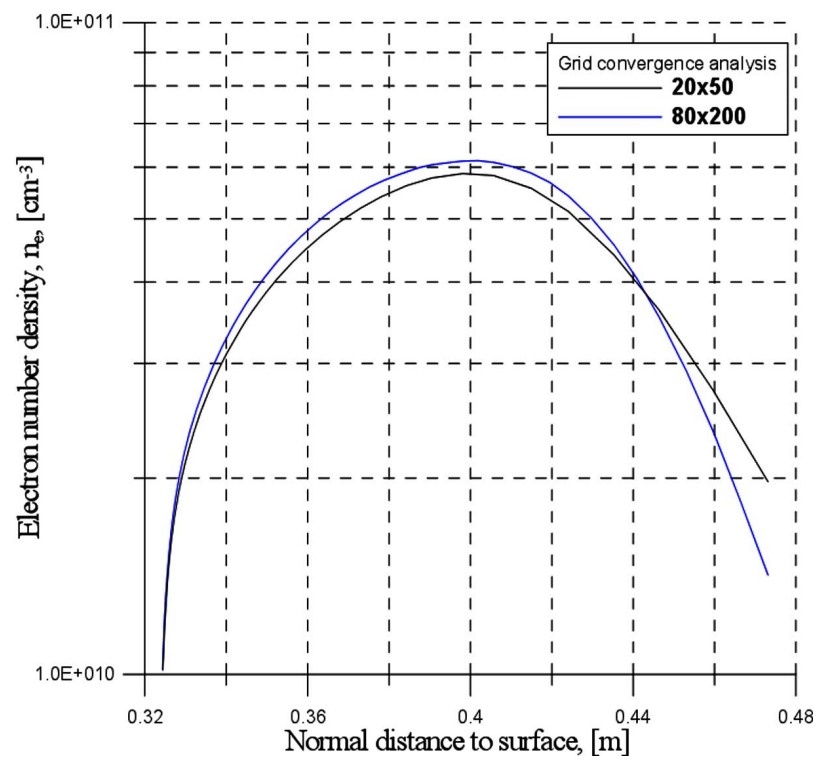

Fig. (3). Electron number densities computed for three different grid sizes $(20 \times 50,40 \times 100,80 \times 200)$.

The simulated flight data refer to two different flight conditions corresponding to altitudes of about 70 and $80 \mathrm{~km}$, along the re-entry trajectory of RAM C-II vehicle. Fig. (4) shows the electron number density profile, normal to the surface, at the location of the electrostatic probe (Fig. 2). It is shown that the best correlation is obtained with the 9 species model from [5]. The good agreement is found at both the altitudes of about 70 and $80 \mathrm{~km}$, with flow conditions shown in Table 2.

Table 2. Free Stream Conditions for the Validation Procedure

\begin{tabular}{|c|c|}
\hline $\mathbf{7 0} \mathbf{~ k m}$ & $\mathbf{8 0} \mathbf{~ k m}$ \\
\hline \hline $\mathrm{M}=25.8$ & $\mathrm{M}=27.6$ \\
\hline $\mathrm{V}=7600 \mathrm{~m} / \mathrm{s}$ & $\mathrm{V}=7800 \mathrm{~m} / \mathrm{s}$ \\
\hline $\mathrm{p}=4.56 \mathrm{~Pa}$ & $\mathrm{p}=1.05 \mathrm{~Pa}$ \\
\hline $\mathrm{T}=217.2 \mathrm{~K}$ & $\mathrm{~T}=198.6 \mathrm{~K}$ \\
\hline
\end{tabular}

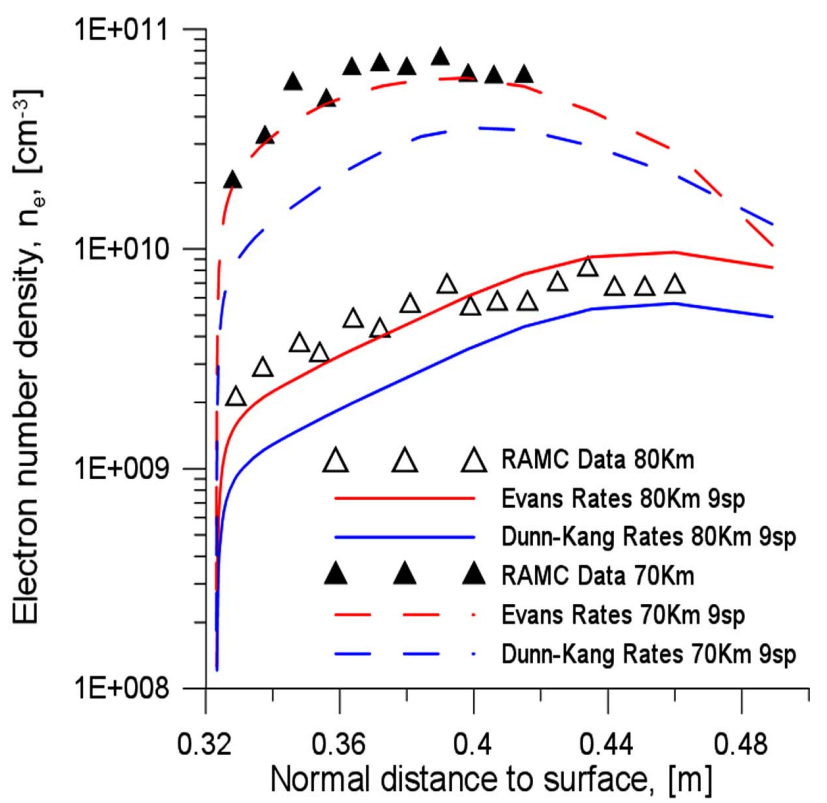

Fig. (4). Electron density profiles as a function of distance from the wall at the probe location; altitudes 70 and $80 \mathrm{~km}$. Experimental data from [5].

In order to assess the effect of different chemical models, numerical results obtained from [4], concerning 7-species and 11-species models, are shown for comparison (Fig. 5). It can be seen that the inclusion of the ionized species $\mathrm{N}^{+}, \mathrm{O}^{+}$, $\mathrm{N}_{2}^{+}$, and $\mathrm{O}_{2}^{+}$is important especially at higher altitudes.

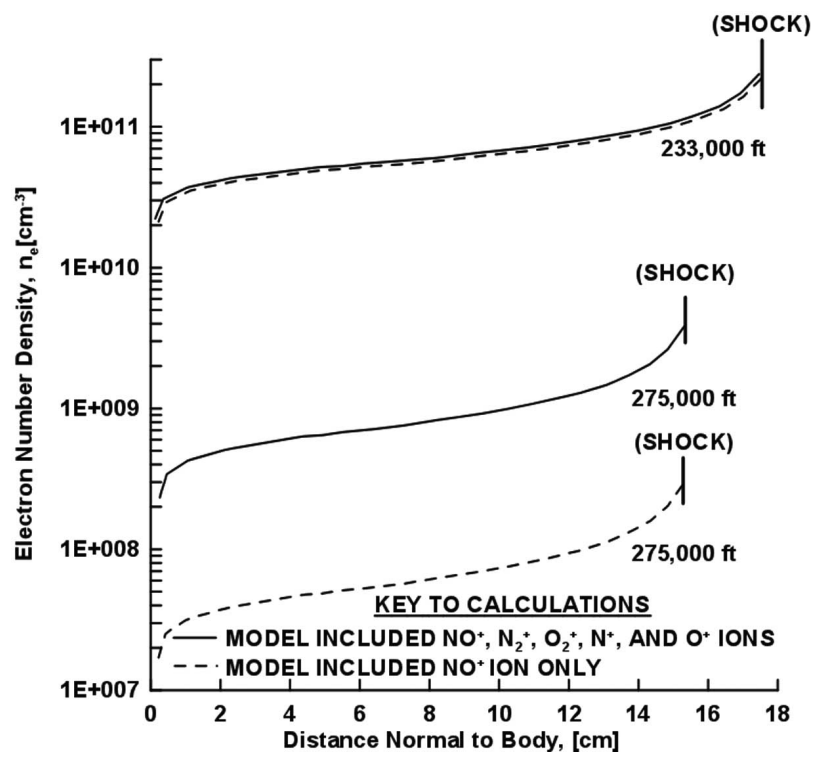

Fig. (5). Electron density profiles as a function of distance from the wall at the probe location, at altitudes 70 and $80 \mathrm{~km}$, as taken from ref. [4]. 


\subsection{Application of the Model to Sharp Re-Entry Configurations}

Particular attention has been focused on slender configurations that, due to the recent advancements in high temperature protection materials, are becoming feasible concept configurations for hypersonic re-entry missions both from LEO and from interplanetary missions [18-21]. In addition, higher and higher attention is being put on re-entry safety issues. Slender configurations could be a possible answers to these issues, with more controllable, airplanelike, configurations replacing the more uncomfortable, and intrinsically unsafe, capsule-type re-entry systems. These lower risk systems [18], imply small angles of attack and long duration flights, i.e. gentle decelerations, at high altitudes; particularly, as a consequence of the gently deceleration, the kinetic energy dissipation rate and heat fluxes are (apart from the stagnation region, that requires special protection) dramatically lower than typical re-entry values. Furthermore, long duration flights allow larger reentry windows, while slender shapes provide operational advantages like increased down and cross-range.

The slender vehicle considered in this work is shown in Fig. (6), as a result of the study performed in [20, 21]. The corresponding trajectories, together with the selected altitude-velocity points for the numerical investigations, are shown in Fig. (7).

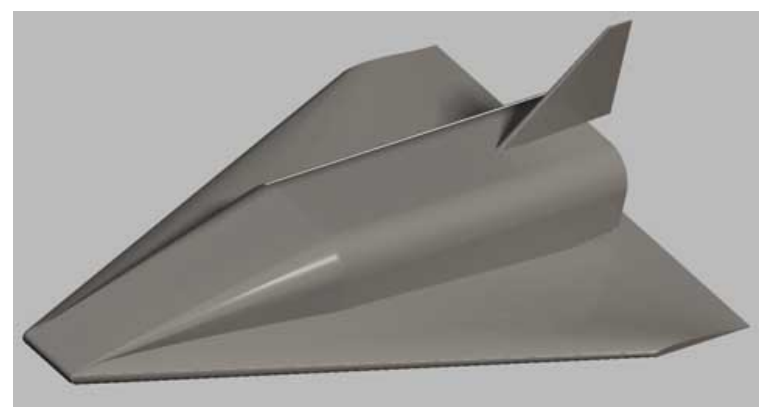

Fig. (6). Image of the PHOEBUS spaceplane [18, 19].

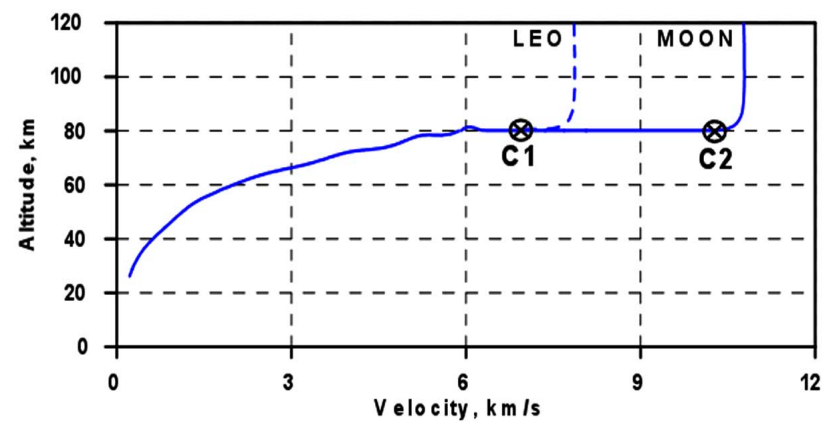

Fig. (7). PHOEBUS re-entry trajectories from Moon and Low Earth Orbit (LEO) [18, 19].

The $\mathrm{C} 1$ and $\mathrm{C} 2$ conditions were considered in this study, representing the critical points when re-entering from LEO mission (C1) or Moon mission (C2)

These are characterised by the freestream conditions reported in Table 3 .
Table 3. Free-Stream Conditions

\begin{tabular}{|c|c|}
\hline $\mathbf{C 1}$ & $\mathbf{C 2}$ \\
\hline \hline $\mathrm{M}=25$ & $\mathrm{M}=38$ \\
\hline $\mathrm{z}=85 \mathrm{Km}$ & $\mathrm{z}=85 \mathrm{Km}$ \\
\hline $\mathrm{V}=7117 \mathrm{~m} / \mathrm{s}$ & $\mathrm{V}=10800 \mathrm{~m} / \mathrm{s}$ \\
\hline $\mathrm{AoA}=0$ & $\mathrm{AoA}=0$ \\
\hline $\mathrm{p}=1.038 \mathrm{~Pa}$ & $\mathrm{p}=1.038 \mathrm{~Pa}$ \\
\hline $\mathrm{T}=198.5 \mathrm{~K}$ & $\mathrm{~T}=198.5 \mathrm{~K}$ \\
\hline $\mathrm{H}=25.2 \mathrm{MJ} / \mathrm{Kg}$ & $\mathrm{H}=58.3 \mathrm{MJ} / \mathrm{Kg}$ \\
\hline
\end{tabular}

Since antennas are situated along the centerline a two dimensional approach was used. Two-dimensional geometries were obtained considering the centerline of the vehicle, shown in Fig. (6), and three different nose cap radii $\left(R_{n}=1,5\right.$ and $\left.10 \mathrm{~cm}\right)$, for a total length of about $9 \mathrm{~m}$.

All three geometries have been investigated with a fully catalytic wall condition, a wall temperature of $1000 \mathrm{~K}$ and an angle of attack of $10^{\circ}$.

Fig. (8) shows, as an example, the contours of temperature for the trajectory point $\mathrm{C} 1$ and for a nose radius of $10 \mathrm{~cm}$. The temperature behind the shock wave rises sharply to $14000 \mathrm{~K}$, and then decreases to the imposed value $(1000 \mathrm{~K})$ on the wall.

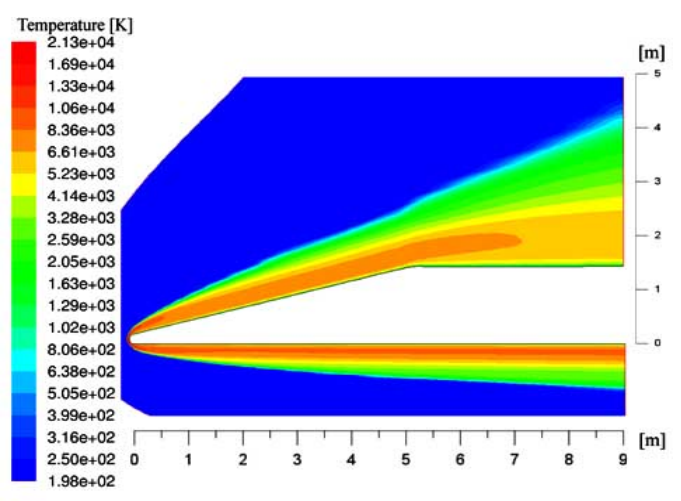

Fig. (8). Contours of temperature $(\mathrm{K})$. Condition $\mathrm{C} 1, \mathrm{R}=10 \mathrm{~cm}$.

Different considerations can be made on these results, with regard to communication black-out prevention or mitigation, by examining the influence of bluntness, antenna location and freestream conditions.

\subsubsection{Bluntness Effect}

Nose curvature affects the electron number density both in the stagnation zone and in the shock layer downstream of the leading edge, i.e. around the possible antenna locations. In the stagnation region, higher bluntness means higher shock stand-off distance, and, therefore, the flow relaxation time becomes sufficient for the ionization reactions to be completed. Then, electrons are convected away from the stagnation zone, along the vehicle surface. Even if the flow 
temperature decreases along the body, electrons do not disappear in the flow, since chemical equilibrium conditions are not attained. On the contrary, this transport process is characterized by almost frozen chemistry, so that a relatively small difference exists between the number density values in the stagnation zone and at the antenna locations.

In Fig. (9), the electron number density profile for all the three geometries, assuming that the antenna is located at $\mathrm{X}=4.5 \mathrm{~m}$ from the nose, is shown, for the $\mathrm{C} 1$ condition. From this figure we can see that the maximum electron number densities drop about four orders of magnitude (from $\sim 10^{10}$ to $\sim 10^{6}$ ), by reducing the curvature radius from 10 to 1 $\mathrm{cm}$. Furthermore, the plasma thickness at $\mathrm{R}=1 \mathrm{~cm}$, is about one half the value at $R=10 \mathrm{~cm}$.

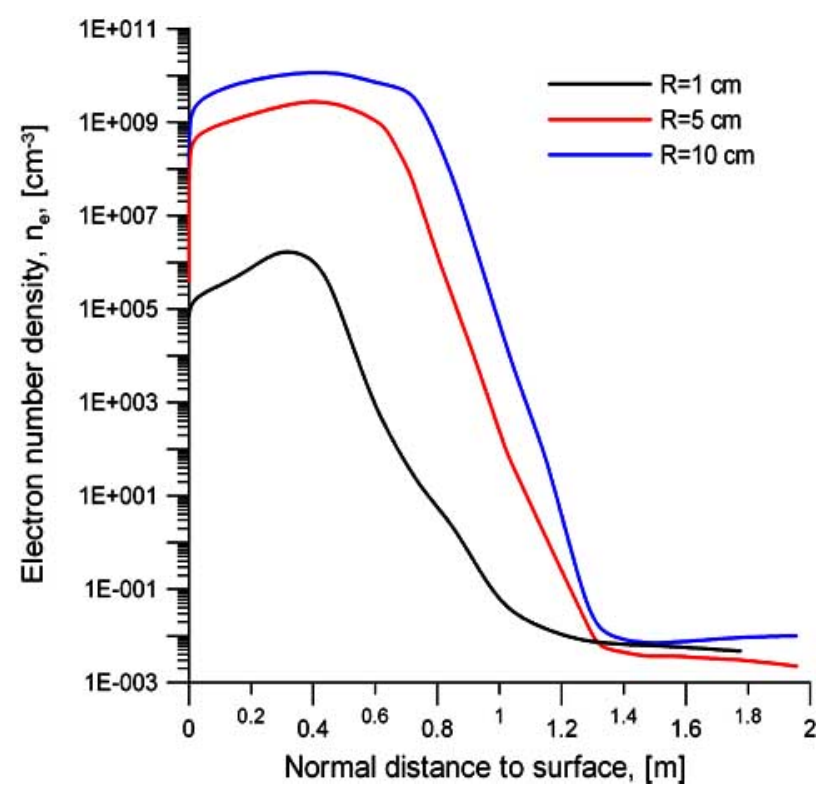

Fig. (9). Electron number density profiles for all the three geometries at $\mathrm{X}=4.5 \mathrm{~m}$ and for $\mathrm{C} 1$ condition.

For the $\mathrm{R}=1 \mathrm{~cm}$ case, bluntness effects are limited to a very small region around the nose, and two almost oblique shock waves on the vehicle windside and leeside appear. Consequently, the ionization degree is much lower, both in the stagnation region (due to the small stand-off distance) and in the rest of the shock layer. This is beneficial with respect to the communication black-out problem, since the maximum electron number density in this case is significantly lower.

All the considerations made for the $\mathrm{C} 1$ condition can be applied to the $\mathrm{C} 2$ condition. The most noticeable difference is the reduction of the stand-off distance and of the shock layer thickness, as a consequence of the increase of the Mach number.

For the $\mathrm{C} 2$ condition, the peak electron number density for the three geometries $(\mathrm{R}=10,5$ and $1 \mathrm{~cm}$, respectively) are $4.6 \cdot 10^{13}, 3.5 \cdot 10^{13}$, and $2.5 \cdot 10^{12}$ electrons per cubic centimeter.

It must be noted that the computed values of the radiative equilibrium temperatures at the stagnation point, for the sharpest case $(\mathrm{R}=1 \mathrm{~cm})$, are of the order of $2500 \mathrm{~K}$, which are values allowable, according to recently studies, for thermal protection systems based on Ultra High Temperature Ceramics (UHTC) $[22,23]$. In any case, the applicability of a sharp configuration for atmospheric re-entry, also from an aero-thermo-dynamic point of view, has already been proved [18-21].

\subsubsection{Antenna Location Effect}

An important effect to be investigated while studying communication black-out phenomena around a re-entry vehicle is linked to the antenna location. In Fig. (11), the electron number density profiles around the intermediate bluntness configuration $(\mathrm{R}=5 \mathrm{~cm})$ are analysed, at four possible antenna locations $(X=2.5,4.5,6,8.5 \mathrm{~m}$, Fig. 10).

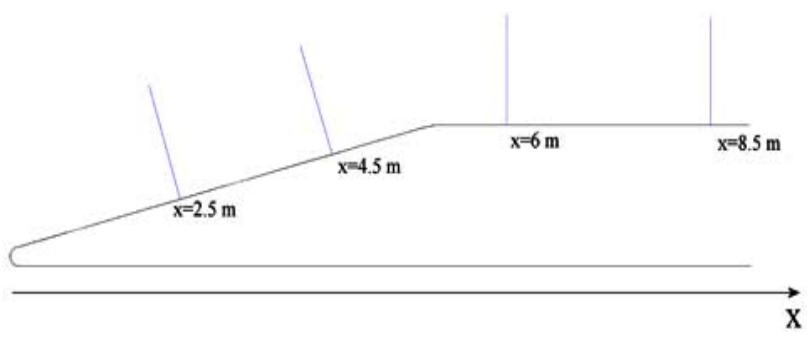

Fig. (10). Antenna locations considered in the study.

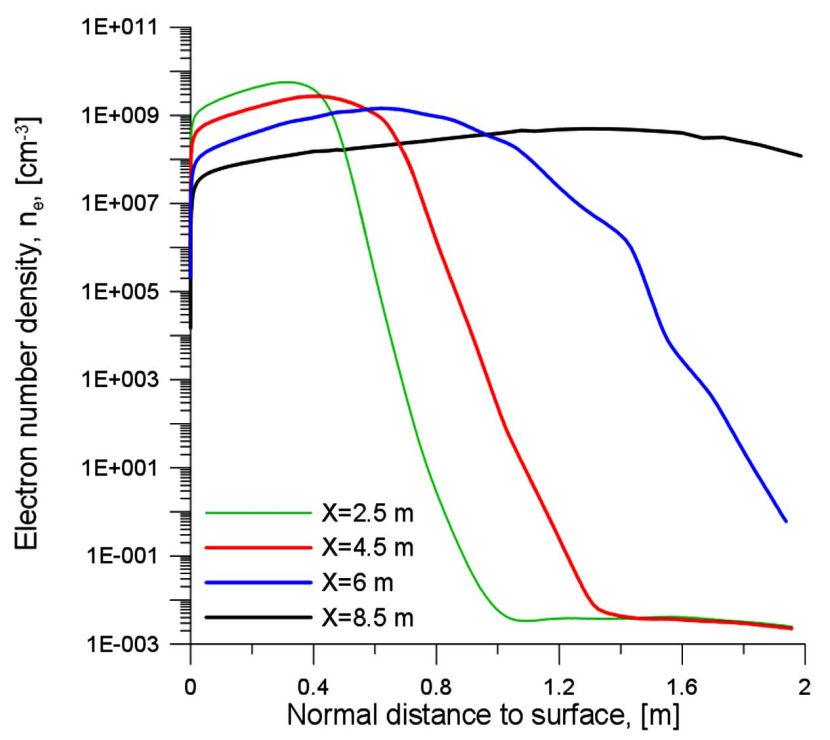

Fig. (11). Electron number density profiles for $\mathrm{R}=5 \mathrm{~cm}$ and $\mathrm{C} 1$ condition, at four possible antenna locations.

It can be seen that plasma thickness rises from about 40 $\mathrm{cm}$ at $\mathrm{X}=2.5 \mathrm{~m}$ to about $2 \mathrm{~m}$ at $\mathrm{X}=8.5 \mathrm{~m}$. However, as the plasma layer thickness increases in the afterbody positions, its maximum electron density decreases (from $\sim 6 \cdot 10^{9}$ at $\mathrm{X}=2.5 \mathrm{~m}$ to $\sim 5 \cdot 10^{8}$ at $\mathrm{X}=8.5 \mathrm{~m}$ ), a condition that is beneficial with regard to plasma attenuation. As a general rule, antenna should be placed as far as possible from the stagnation region, and, if possible, in the vehicle base region, where, due to the shadow effect, low electron concentrations are expected. 


\subsubsection{Free-Stream Conditions Effects}

Free-stream condition effects, in our case mainly Mach number effects, have been evaluated for all configurations.

In Fig. (12), the results for the intermediate configuration $\left(\mathrm{R}_{\mathrm{n}}=5 \mathrm{~cm}\right)$, and at a fixed antenna location $(\mathrm{X}=4.5 \mathrm{~m})$, have been shown.

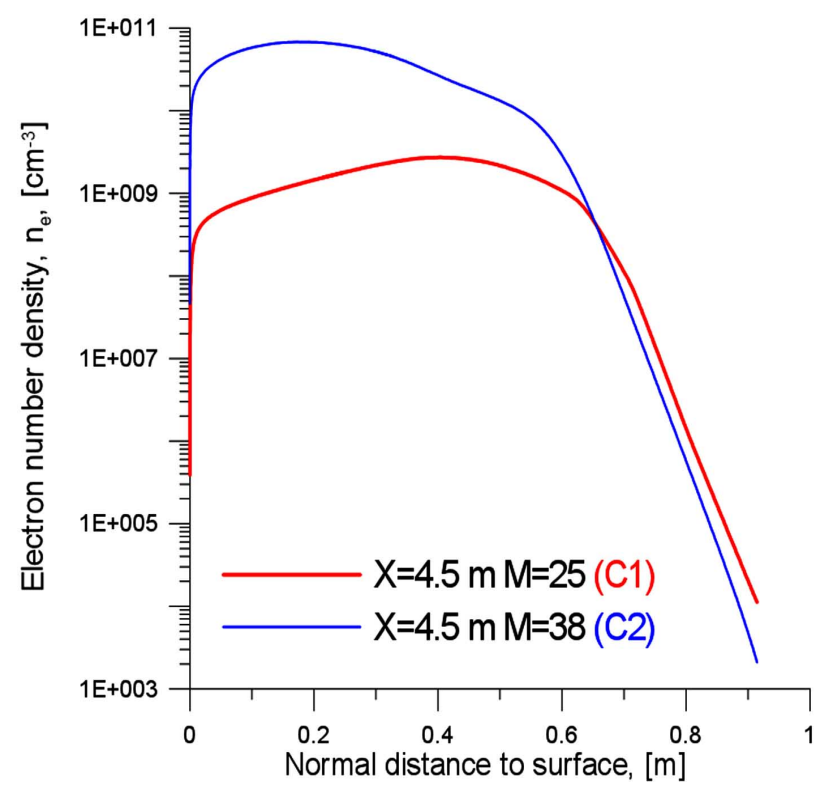

Fig. (12). Electron number density profiles for $\mathrm{R}=5 \mathrm{~cm}$ at $\mathrm{X}=4.5 \mathrm{~m}$, for both $\mathrm{C} 1$ and $\mathrm{C} 2$ conditions.

The main effect that takes place is an increase of the maximum electron number density, which becomes $\sim 20$ times higher for the $\mathrm{C} 2$ condition, due to the higher energy level, i.e. ionization levels, in the shock layer.

\subsubsection{Evaluation of the Electromagnetic Attenuation}

$\mathrm{RF}$ black-out occurrence prediction can be made, as a first approximation, by evaluating the electron number density distributions, and comparing them with the plasma critical density, which is a value directly related to the frequency of the signal to be transmitted. Since the C2 condition is characterised by higher energy, this is the worst case condition to be considered with regard to RF attenuation.

In Fig. (13), the electron density distributions for the considered geometries at a fixed body position are shown. The plasma critical density for the $1.575 \mathrm{GHz}$ GPS signal, which has a value of $3 \cdot 10^{10}$ electrons $/ \mathrm{cm}^{3}$, has been superimposed.

From this figure we can note that RF black-out does not occur for the most slender configuration $(\mathrm{R}=1 \mathrm{~cm})$, since the maximum electron number density is at least an order of magnitude lower than the critical one. The same result can be extended, "a fortiori", to the $\mathrm{C} 1$ condition. However, RF signal attenuation should occur for both the other two geometries $(\mathrm{R}=5$ and $10 \mathrm{~cm})$. Indeed, in these cases, electron number density curves are above the critical value for most of the plasma layer.

\subsubsection{Synthesis of the Numerical Investigations}

An aero-thermo-dynamic model has been developed to study the plasma flow during hypersonic re-entry of space vehicles. The core of the model is a 9-species mixture, including electron, treated as an independent gas species, in chemical non-equilibrium and thermal equilibrium. The model has been first validated against the in-flight measurements of the RAM-C experimental test-bed, and then applied to a slender vehicle geometry, which is expected to be less influenced by radio signal attenuation. Three effects have been analyzed, namely nose bluntness, antenna location, and freestream Mach number. The results, generalized introducing non-dimensional quantities, are shown in Tables 4-6.

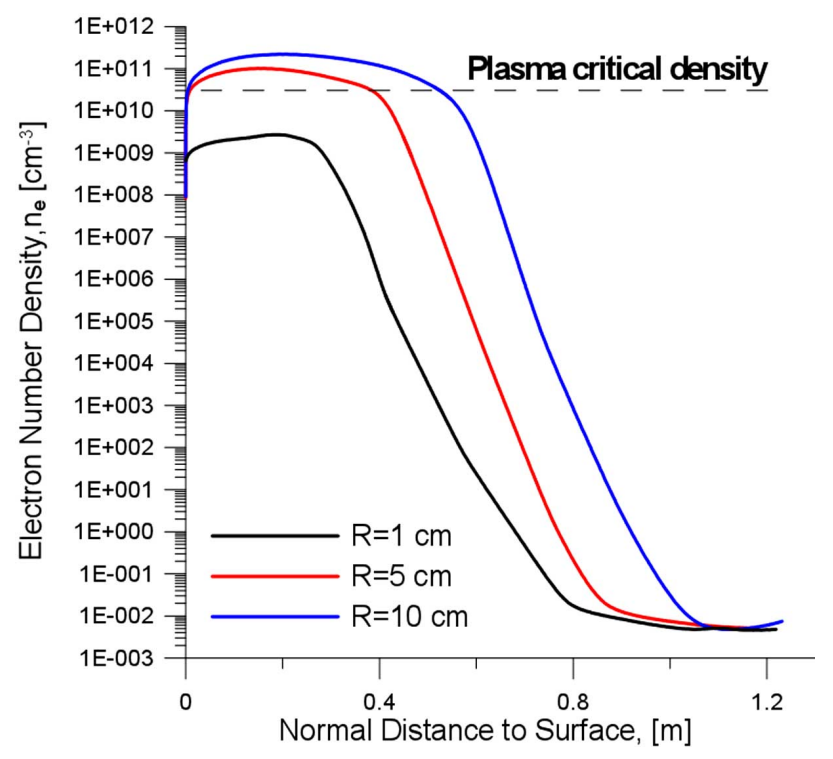

Fig. (13). Electron number density profiles for all the three geometries at $\mathrm{X}=2.5 \mathrm{~m}$ and for $\mathrm{C} 2$ condition.

Table 4. Effect of Nose Bluntness

\begin{tabular}{|c|c|c|}
\hline $\mathbf{R} / \mathbf{L}$ & $\mathbf{X}_{\mathbf{A}} / \mathbf{L}$ & $\mathbf{n}_{\mathbf{e}, \mathbf{m a x}} / \mathbf{n}_{\mathbf{e}, \mathbf{r r}}$ \\
\hline \hline $1.1 \mathrm{e}-3$ & 0.5 & $1.1 \mathrm{e}-4$ \\
\hline $5.5 \mathrm{e}-3$ & 0.5 & 0.11 \\
\hline $1.1 \mathrm{e}-2$ & 0.5 & 0.52 \\
\hline
\end{tabular}

Table 5. Effect of Antenna Location

\begin{tabular}{|c|c|c|}
\hline $\mathbf{X}_{\mathbf{A}} / \mathbf{L}$ & $\mathbf{R} / \mathbf{L}$ & $\mathbf{n}_{\mathbf{e}, \mathbf{m a x}} / \mathbf{n}_{\mathbf{e}, \mathbf{r r}}$ \\
\hline \hline 0.28 & $5.5 \mathrm{e}-3$ & 0.26 \\
\hline 0.5 & $5.5 \mathrm{e}-3$ & 0.11 \\
\hline 0.67 & $5.5 \mathrm{e}-3$ & 0.079 \\
\hline 0.94 & $5.5 \mathrm{e}-3$ & 0.0078 \\
\hline
\end{tabular}

It must be underlined that the ratio between the maximum electron number density in the shock layer and the 
critical number density for that particular signal, gives only an approximate evaluation of the radio signal attenuation. A detailed attenuation computation should be carried out by integrating the electromagnetic equations along the antenna line-of-sight. Such calculations are however outside the scope of this work.

Table 6. Effect of Mach Number

\begin{tabular}{|c|c|c|c|}
\hline $\mathbf{M}$ & $\mathbf{R} / \mathbf{L}$ & $\mathbf{X}_{\mathbf{A}} / \mathbf{L}$ & $\mathbf{n}_{\mathbf{e}, \mathbf{m a x}} / \mathbf{n}_{\mathbf{e}, \mathbf{c r}}$ \\
\hline \hline 25 & $5.5 \mathrm{e}-3$ & 0.5 & 0.19 \\
\hline 38 & $5.5 \mathrm{e}-3$ & 0.5 & 2.1 \\
\hline
\end{tabular}

\section{ARC-JET FACILITY SET-UP FOR ON-GROUND SIMULATION OF COMMUNICATION BLACK-OUT PHENOMENA}

Objective of this section is to describe the experimental activities dedicated to explore the simulation capabilities of an arc-jet facility with regard to radio communication blackout phenomena.

A plasma wind tunnel facility is available at DIAS to study specific problems of hypersonic aerodynamics, with particular attention to aero-heating and fluid-structure interactions and for test of Thermal Protection Systems (TPS) materials. In this study, the possibility to extend the facility capabilities for the study of black-out communication problems is investigated.

The SPES (Small Planetary Entry Simulator) facility is a continuous, open-circuit, blow-down arc facility including:

- A $80 \mathrm{~kW}$ plasma torch that operates with inert gas ( $\mathrm{He}, \mathrm{N}_{2}, \mathrm{Ar}$ and their mixture) at mass flow rates up to $5 \mathrm{~g} / \mathrm{s}$. Specific total enthalpies up to $18 \mathrm{MJ} / \mathrm{kg}$ are achieved at gas mass flow rate of $1 \mathrm{~g} / \mathrm{s}$.

- Different convergent-divergent nozzle where the flow expands to a nominal Mach number up to 4.8.

- A test chamber with infrared and optical windows.

- A vacuum system characterized by three stage system composed by mechanical pumps and two boosters allowing a pressure below $100 \mathrm{~Pa}$.

- A swirl mixer where a second gas can be supplied to obtain desired atmosphere composition.

- Automatic control system allows monitoring the facility main parameter (Arc heater voltage and current, water cooling temperature, mass flow rate and pressure).

In the frame of this study, a preliminary characterization of the plasma jet has been done using Langmuir probes, that provide a powerful and experimentally simple way to characterize basic plasma parameters, in particular plasma density and electron temperature (see e.g. [24]).

A Langmuir probe is a small metallic wire in contact with a plasma which can be biased relative to the plasma. The current collected by the probe is measured as a function of the probe bias.
Although the probes is fairly straightforward to operate, analysis of probe data is quite complicated because there is no universal method of interpretation $[25,26]$. In Fig. (14), the Argon plasma jet during operations is shown, together with the Langmuir probe measuring plasma ionization levels outside the nozzle exit.

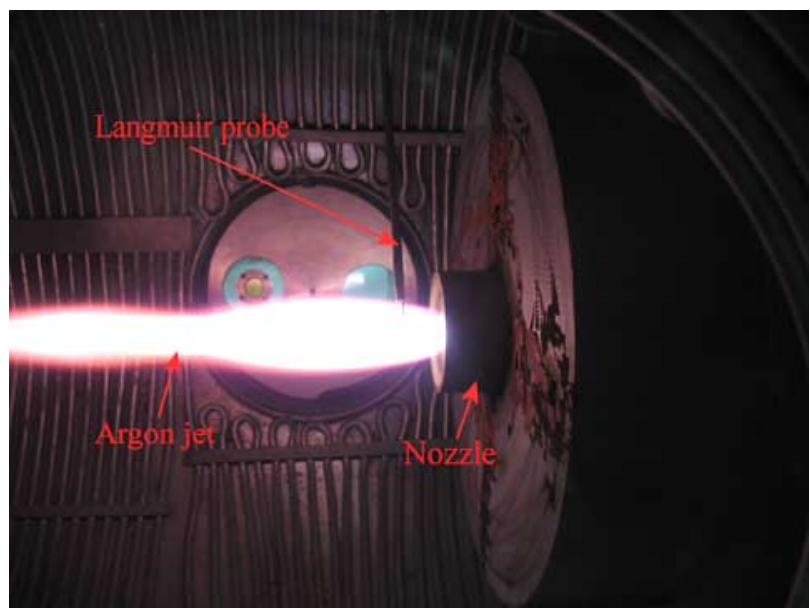

Fig. (14). Argon jet in the test chamber during the experimental test. The Langmuir probe is also shown.

Laframboise's theory was used to analyze the Langmuir probe data [25], analyzing the electron current to the probe, $\mathrm{I}_{e}$, in the transition region of the current-voltage (I-V) characteristics (assuming Maxwellian electron distribution [27]).

Experiments have been carried out at plasma flow conditions corresponding to an arc current of $250 \mathrm{~A}$ and to a mass flow rate of $1 \mathrm{~g} / \mathrm{s}$, i.e. to a specific total enthalpy at the torch exit of about $8 \mathrm{MJ} / \mathrm{Kg}$. The measured electron density and temperature, together with the experimental uncertainties, are summarized in Table 7.

Table 7. Experimental Test Conditions and Measured Ionization Level and Energy

\begin{tabular}{|c|c|c|c|c|c|}
\hline Gas & $\mathbf{I}[\mathbf{A}]$ & $\mathbf{m}[\mathbf{g} / \mathbf{s}]$ & $\mathbf{H}_{\mathrm{te}}[\mathbf{M J} / \mathbf{k g}]$ & $\mathbf{n}_{\mathrm{e}}\left[\mathbf{c m}^{-3}\right]$ & $\mathbf{T}_{\mathrm{e}}[\mathbf{K}]$ \\
\hline \hline Argon & 250 & 1.0 & 8 & $10^{11}-10^{12}$ & $5000 \pm 10 \%$ \\
\hline
\end{tabular}

These results confirm that the SPES facility can be used for the purpose of simulation of communication blackout/attenuation problems, since the ionization levels in the flow are of the same order of magnitude as those encountered during re-entry.

\section{WIND TUNNEL SIMULATIONS AND COR- RELATIONS WITH THE EXPERIMENTAL RESULTS}

In order to correlate the experimental results, a numerical model of an Argon plasma in chemical and thermodynamic non-equilibrium has been developed, based on the work by Hoffert and Lien [28]. In particular, an electron temperature is introduced to evaluate the electron energy, and first Argon ionization is included as the dominant chemical reaction. 
Two reaction rates are however considered, distinguishing between the electron and Argon as third bodies (Table 8).

The flow in the plasma torch and the nozzle of the SPES facility has been simulated. The gas heating by the electric arc has been modelled as a constant heat source in the energy equation. The numerical scheme is the same as described in the previous section.

Table 8. Chemical Reactions Considered in the Argon Plasma Model

\begin{tabular}{|c|c|}
\hline Reaction & Third Body $\boldsymbol{M}$ \\
\hline \hline $\mathrm{Ar}+\mathrm{M}_{1} \Leftrightarrow \mathrm{Ar}^{+}+\mathrm{e}^{-}+\mathrm{M}_{1}$ & $\mathrm{Ar}$ \\
\hline $\mathrm{Ar}+\mathrm{M}_{2} \Leftrightarrow \mathrm{Ar}^{+}+\mathrm{e}^{-}+\mathrm{M}_{2}$ & $\mathrm{e}^{-}$ \\
\hline
\end{tabular}

The resulting distributions of electron densities and temperature, for the case corresponding to Table 7, are shown in Fig. (15a, b). The values obtained at the nozzle exit are in agreement with the measured values reported in the previous section, as shown in Table 9.

(a)

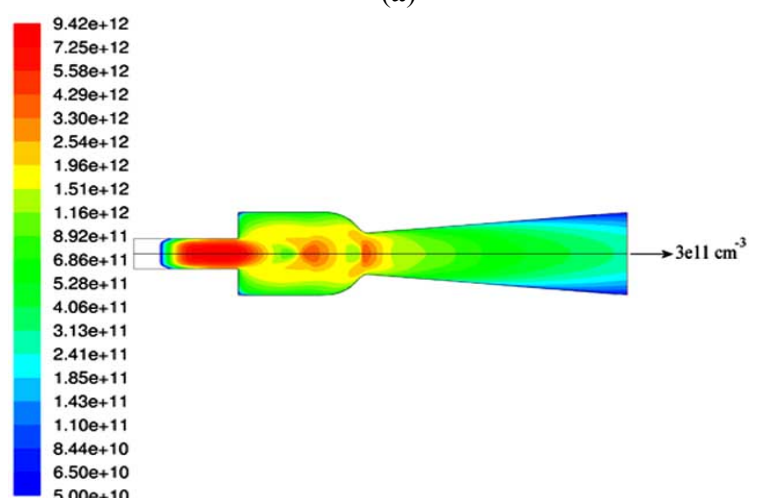

(b)

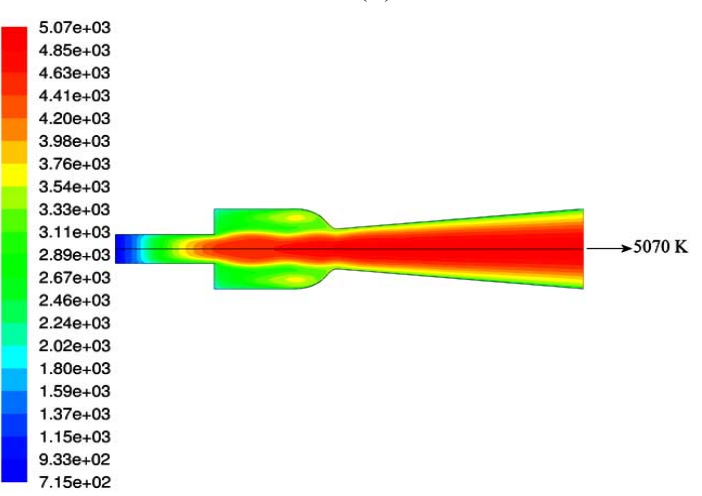

Fig. (15). Electron density $\left(\mathbf{a}, \mathrm{cm}^{-3}\right)$ and electron temperature $(\mathbf{b}, \mathrm{K})$ of the argon plasma flow inside the torch and the nozzle ( $\mathrm{I}=250 \mathrm{~A})$

Table 9. Comparison Between Experimental and Numerical Results for the Argon Plasma Flow

\begin{tabular}{|c|c|c|}
\hline & Experimental & Numerical \\
\hline \hline $\mathrm{n}_{\mathrm{e}}\left[\mathrm{cm}^{-3}\right]$ & $10^{11}-10^{12}$ & $3 \cdot 10^{11}$ \\
\hline $\mathrm{T}_{\mathrm{e}}[\mathrm{K}]$ & $5000 \pm 10 \%$ & 5070 \\
\hline
\end{tabular}

\section{CONCLUSIONS}

A numerical model has been developed and validated to study electromagnetic waves attenuation by plasmas surrounding hypersonic reentry vehicles in atmospheric flight. A large effort has been dedicated to undertake an experimental activity using a continuous blow-down high enthalpy arc facility to define a suitable plasma flow modelling and experimental set-up to estimate the plasma frequencies during a typical re-entry trajectory and to correlate radiofrequency signal loss or attenuation.

The numerical code, implemented for the simulations of typical re-entry vehicles and able to correlate electronic densities was validated against experimental data of RAM-C (NASA) flight experiments (in the order $10^{11}-10^{14} / \mathrm{cm}^{3}$ ). A systematic investigation of the influence of the vehicle geometry and flight conditions has been presented. In particular, slender vehicles with relatively sharp leading edges, flying at moderate angles of attack, imply weaker shock wave and lower electronic density, resulting in the attenuation of black out phenomena.

Future activities will be dedicated to the extension of these results, to a comprehensive analysis to reproduce a large variety of flight plasma environments in the on-ground arc-jet facility, by means of proper calibration to fit the reentry trajectory point of selected re-entry vehicles.

Ad-hoc antenna probes are under design to study plasma radiofrequency interaction in arc-jet and around re-entry vehicles for characterization of the electro-magnetic behaviour in the plasma sheath at specific locations of the vehicle along the re-entry flight path.

\section{LIST OF SYMBOLS}

$\begin{array}{lll}\text { AoA } & = & \text { Angle of attack }(\mathrm{deg}) \\ \mathrm{H} & = & \text { Specific total enthalpy }(\mathrm{J} / \mathrm{kg}) \\ \mathrm{I} & = & \text { Arc Current }(\mathrm{A}) \\ \mathrm{M} & = & \text { Mach number } \\ \mathrm{m} & = & \text { Mass flow rate }(\mathrm{kg} / \mathrm{s}) \\ \mathrm{n}_{\mathrm{e}} & = & \text { Electron number density }\left(\mathrm{cm}^{-3}\right) \\ \mathrm{p} & = & \text { Pressure }(\mathrm{Pa}) \\ \mathrm{R} & = & \text { Nose radius }(\mathrm{m}) \\ \mathrm{T} & = & \text { Temperature }(\mathrm{K}) \\ \mathrm{T}_{\mathrm{e}} & = & \text { Electron temperature }(\mathrm{K}) \\ \mathrm{V} & = & \text { Velocity }(\mathrm{m} / \mathrm{s}) \\ \mathrm{X} & = & \text { Longitudinal coordinate }(\mathrm{m})\end{array}$

\section{REFERENCES}

[1] J.C. Paulat, P. Boukhobza, "Re-entry Flight Experiments Lessons Learned - The Atmospheric Reentry Demonstrator, ARD", in Flight Experiments for Hypersonic Vehicle Development, Educational Notes RTO-EN-AVT-130, Paper 10, Neuilly-sur-Seine, France, pp. 10-1, 10-46, 2007.

[2] R.A. Hartunian, G.E. Stewart, S.D. Fergason, T.J. Curtiss and R.W. Seibold, "Causes and Mitigation of Radio Frequency (RF) Blackout During Reentry of Reusable Launch Vehicles", Aerospace Report No. ATR-2007(5309)-1, pp. 1-69, January 2007. 
[3] R. Lehnert, B. Rosenbaum, "Plasma Effects on Apollo Re-entry Communication", NASA TN D-2732, pp. 1-15, March 1965.

[4] M.G. Dunn, S. Kang, "Theoretical and Experimental Studies of Reentry Plasmas", NASA CR-2232, pp. 1-44, April 1973.

[5] J.S. Evans, C.J. Shexnayder Jr., P.W. Hubert, "Boundary-Layer Profiles for a Entry of a Blunt Slender Body at High Altitude", NASA TN D-7332, pp. 1-38, July 1973.

[6] D.D. Morabito, "The Spacecraft Communications Blackout Problem Encountered during Passage or Entry of Planetary Atmospheres", IPN Progress Report 42-150, pp. 1-23, August 2002.

[7] F. J. Tischer, "A Rough Estimate of the 'Blackout' Time in ReEntry Communications", Goddard Space Flight Center Document X-520-62-93, June 1962.

[8] F. J. Tischer, "Attenuation in Re-Entry Communications," Goddard Space Flight Center Document X-520-62-92, June 1962.

[9] F. J. Tischer, "On Communications Along Apollo-Type Re-Entry Trajectories", GoddardSpace Flight Center Document X-520-62159, September 1962.

[10] F. J. Tischer, "On the Elimination of the Communications Blackout at Re-Entry from Super-Orbital Flights", Goddard Space Flight Center Document X-520-62- 172, October 1962.

[11] M.J. Nusca and G.R. Cooper, "Computational simulation of EM attenuation by plasmas formed in hypervelocity atmospheric flight", 8th AIAA International Spaceplanes and Hypersonic Systems and Technology Conference, AIAA paper 98-1573, 1998.

[12] P. A. Gnoffo, R. N. Gupta and J. L. Shinn, "Conservation equations and physical models for hypersonic air flows in thermal and chemical nonequilibrium", NASA-TP-2867, pp. 1-58, February 1989.

[13] G. V. Candler, "The Computation of Weakly Ionized Flow in Nonequilibrium", PhD thesis, Stanford University, California, June 1988.

[14] G.S.R. Sarma, "Physico-chemical modelling in hypersonic flow simulation”, Prog. Aerospace Sci., vol. 36, pp. 281-349, 2000.

[15] R. N. Gupta, J. M. Yos, R. A. Thompson, "A Review of Reaction Rates and Thermodynamic and Transport Properties for the 11Species Air Model for Chemical and Thermal Nonequilibrium Calculations to 30000 K", NASA Technical Memorandum 101 528, pp. 1-68, February 1989.

[16] Fluent 6.3 User's Guide, Fluent Inc., Lebanon, NH, USA, 2006.
[17] W. L. Jones, Jr., A. E. Cross, "Electrostatic-probe measurements of plasma parameters for two reentry flight experiments at 25000 feet per second", NASA TN D-6617, pp. 1-67, February 1972.

[18] R Monti, D. Paterna, R. Janovsky, "Flight Physics for a Vehicle Along a Low Risk Re-entry Trajectory", in European Conference for Aerospace Sciences, Moscow, 2005.

[19] R. Monti,, R. Janovsky, R. Savino, M. De Stefano Fumo, "Exploiting lift force in re-entry from exploration missions", in International Symposium : To Moon and Beyond, Bremen, 2007.

[20] M. Tausche, R. Janovsky, M. Scheper, J. Apeldoorn, R. Monti, R. Savino, M. De Stefano Fumo, D. Paterna, E. Di Sotto, J. Branco, R. Molina, "PHOEBUS: A High Lift-over-Drag Vehicle for Earth Reentry", in 16th AIAA/DLR/DGLR International Space Planes and Hypersonic Systems and Technologies Conference, Bremen, Germany, October 2009.

[21] M. Tausche, Dr. R. Janovsky, M. Scheper, J. Apeldoorn, R. Monti, R. Savino, M. De Stefano Fumo, D. Paterna, E. Di Sotto, R. Molina, "SpacePlane: A High Lift-over-Drag Vehicle for Earth Reentry", in 60th International Astronautical Congress (IAC), Daejeon, Republic of Korea, October 2009.

[22] F. Monteverde, R. Savino, M. De Stefano Fumo, A. Di Maso, "Plasma wind tunnel testing of ultra-high temperature $\mathrm{ZrB} 2-\mathrm{SiC}$ composites under hypersonic re-entry conditions", J. Eur. Ceram. Soc., vol. 30, no. 11, pp. 2313-2321, August 2010.

[23] M. Gasch, D. Ellerby, E. Irby, S. Beckman, M. Gusman, S. Johnson, "Processing, properties and arc jet oxidation of hafnium diboride/silicon carbide ultra high temperature ceramics", J. Mater. Sci., vol. 39, pp. 5925 - 5937, 2004.

[24] C.-K. Kim, "Analysis of langmuir probe data in high density plasmas", Korean J. Chem. Eng., vol. 21, no. 3, pp. 746-751, 2004.

[25] J. G. Laframboise, "Theory of Spherical And Cylindrical Langmuir Probes in a Collisionless, Maxwellian Plasma at Rest", Report No. 100, Univ. of Toronto, Inst. Aerospace Studies, 1966. Available: http://www.dtic.mil/cgi-bin/GetTRDoc?Location=U2\&doc=GetTR Doc.pdf\&AD=AD0634596.

[26] R. L. Merlino, "Understanding Langmuir probe current-voltage characteristics", Am. J. Phys., vol. 75, no. 12, pp. 1078-1085, December 2007.

[27] R.M. Clements, "Plasma Diagnostics with electric probes," J. Vac. Sci. Technol., vol. 15, p. 193, 1978.

[28] M. L. Hoffert and H. Lien, "Quasi one-dimensional nonequilibrium gas dynamics of partially ionized two temperature argon", Phys. Fluids, vol. 10, pp. 1769-77, 1967.

Received: May 6, 2010

Revised: June 25, 2010

Accepted: August 4, 2010

(C) Savino et al.; Licensee Bentham Open.

This is an open access article licensed under the terms of the Creative Commons Attribution Non-Commercial License (http: //creativecommons.org/licenses/by$\mathrm{nc} / 3.0 /$ ) which permits unrestricted, non-commercial use, distribution and reproduction in any medium, provided the work is properly cited. 